\title{
Flow induced crystallization prevents melt fracture of HDPE in uniaxial extensional
} flow

Hassager, Ole; Parisi, Daniele; Borger, Anine L.; Mortensen, Kell; Wingstrand, Sara L.

Published in:

Journal of Rheology

Link to article, DOI:

$10.1122 / 1.5038393$

Publication date:

2018

Document Version

Publisher's PDF, also known as Version of record

Link back to DTU Orbit

Citation (APA):

Hassager, O., Parisi, D., Borger, A. L., Mortensen, K., \& Wingstrand, S. L. (2018). Flow induced crystallization prevents melt fracture of HDPE in uniaxial extensional flow. Journal of Rheology, 62(4), 1051-1060.

https://doi.org/10.1122/1.5038393

\section{General rights}

Copyright and moral rights for the publications made accessible in the public portal are retained by the authors and/or other copyright owners and it is a condition of accessing publications that users recognise and abide by the legal requirements associated with these rights.

- Users may download and print one copy of any publication from the public portal for the purpose of private study or research.

- You may not further distribute the material or use it for any profit-making activity or commercial gain

- You may freely distribute the URL identifying the publication in the public portal 
Flow induced crystallization prevents melt fracture of HDPE in uniaxial extensional flow

Sara L. Wingstrand, Ole Hassager, Daniele Parisi, Anine L. Borger, and Kell Mortensen

Citation: Journal of Rheology 62, 1051 (2018); doi: 10.1122/1.5038393

View online: https://doi.org/10.1122/1.5038393

View Table of Contents: https://sor.scitation.org/toc/jor/62/4

Published by the The Society of Rheology

\section{ARTICLES YOU MAY BE INTERESTED IN}

Computing the linear viscoelastic properties of soft gels using an optimally windowed chirp protocol Journal of Rheology 62, 1037 (2018); https://doi.org/10.1122/1.5018715

Contour length fluctuations and constraint release in entangled polymers: Slip-spring simulations and their implications for binary blend rheology

Journal of Rheology 62, 1017 (2018); https://doi.org/10.1122/1.5031072

A generalized frictional and hydrodynamic model of the dynamics and structure of dense colloidal suspensions Journal of Rheology 62, 905 (2018); https://doi.org/10.1122/1.5006937

Shear thinning in dilute and semidilute solutions of polystyrene and DNA

Journal of Rheology 62, 845 (2018); https://doi.org/10.1122/1.5010203

The transient behavior of soft glassy materials far from equilibrium Journal of Rheology 62, 869 (2018); https://doi.org/10.1122/1.5024701

Linear shear and nonlinear extensional rheology of unentangled supramolecular side-chain polymers Journal of Rheology 62, 1155 (2018); https://doi.org/10.1122/1.5012349

\section{Master your flow}

with the MCR Rheometer series
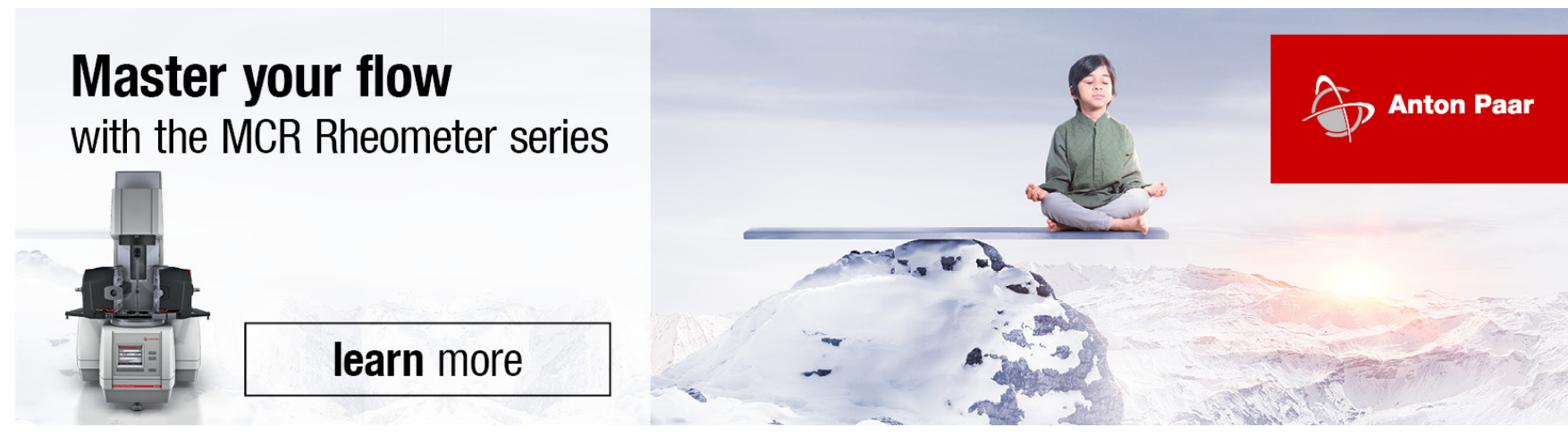


\title{
Flow induced crystallization prevents melt fracture of HDPE in uniaxial extensional flow
}

\author{
Sara L. Wingstrand, ${ }^{1}$ Ole Hassager, ${ }^{1, a)}$ Daniele Parisi, ${ }^{2, b)}$ Anine L. Borger, ${ }^{3}$ and Kell Mortensen ${ }^{3}$ \\ ${ }^{1}$ Department of Chemical and Biochemcial Engineering, Danish Polymer Center, Technical University of Denmark, \\ DK-2800 Kgs. Lyngby, Denmark \\ ${ }^{2}$ Institute of Electronic Structure and Laser, FORTH, Heraklion 71110, Crete, Greece
}

${ }^{3}$ Niels Bohr Institute, X-ray and Neutron Science, University of Copenhagen, DK-2100 København Ø, Denmark

(Received 3 May 2018; final revision received 7 June 2018; published 16 July 2018)

\begin{abstract}
This work concerns extension induced crystallization of a commercial high density polyethylene above the equilibrium melting temperature. We compare the nonlinear response during uniaxial elongation to the morphology obtained in the quenched fibers after cessation of the flow at a Hencky strain of 5 . At $12{ }^{\circ} \mathrm{C}$ above the melting temperature, the samples undergo brittle fracture. Samples stretched at 2 and $6{ }^{\circ} \mathrm{C}$ above the melting temperature remain intact throughout the entire course of deformation and exhibit a strain hardening behavior that does not follow time temperature superposition. We propose that stabilization of the filament at lower temperatures, as well as the failure of time temperature superposition, is caused by flow-induced nucleation and growth of shish structures oriented along the flow direction. Further justification is obtained from small-angle X-ray scattering performed on the quenched filament showing an increased formation of shish with an increase in the deformation rate. We find the critical Hencky strain for the onset of the shish formation to be between 0 and 0.6 , which is significantly lower than the values reported in the existing literature. We model the influence of shish nucleation on the rheological response in an extension using the hierarchical multimode stress function, which is modified to include the stretched network assumption. (C) 2018 The Society of Rheology. https://doi.org/10.1122/1.5038393
\end{abstract}

\section{INTRODUCTION}

It has long been known that deformation enhances the tendency for polymers to crystallize. Flory [1] used equilibrium thermodynamics to explain the effect for crosslinked networks in terms of equilibrium thermodynamics. Basically, the reduction in entropy upon stretching of the polymer chains lowers the entropic penalty in passing to the crystalline state. For flowing polymer melts, the mechanism of the formation of crystalline structures is a more complicated problem, which has yet to be fully understood [2]. Some aspects of the problem have been resolved. Combined rheology and in situ scattering methods have revealed that stretching of the high-molecular-weight fraction upon the application of flow causes the formation of needlelike nuclei $[3,4]$. These nuclei grow into shish structures, and only at a much later stage does the overgrowth of kebabs occur [5]. These needlelike nuclei are believed to be caused by threadlike precursors [6,7]. However, the nature of these precursors, the mechanism of their formation, and transition into nuclei in the flow remain to be resolved. For threadlike precursors to arise, some degree of chain deformation is necessary. The extent of deformation needed, however, is debated

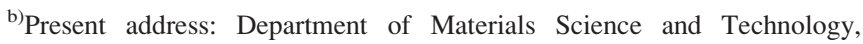
University of Crete, Heraklion 71003, Crete, Greece.

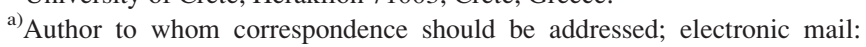
oh@kt.dtu.dk

as well [8] along with considerations on how to interpret a melt containing precursors. Recent experimental studies suggest that considering the nucleating melt as a stretched network [8-11] yields a better description than the traditional coil-stretch transition proposed by Keller and Kolnar [4].

Resolving these questions is important, as flow-induced shish-kebab structures tremendously enhance the mechanical properties of the final material [12]. What is not so often emphasized, however, is the fact that these structures influence the mechanical properties of the melt, too. Recently, Li and coworkers found that after an extensional step strain is imposed on an isotactic polypropylene melt, flow-induced shish prevents the sample from necking. Necking is the result of a flow instability that arises in uncontrolled extension [13-15]. While the failure caused by necking is an interesting and relevant problem, it does not reveal insights into the true strength of the material and the reinforcement upon shish formation. A true fracture experiment can reveal the strength of a melt in extension, as well as the mechanism of failure, as performed by Huang et al. on amorphous systems $[16,17]$. The fracture mechanics of semicrystalline systems undergoing flow-induced crystallization (FIC) have yet to be studied in controlled extension.

In this work, we study a commercial high density polyethylene (HDPE) subjected to controlled uniaxial extensional flow above the melting temperature. We study the reinforcement of the filaments by shish nucleation and growth and its ability to prevent brittle fracture. Using a filament stretch 
rheometer combined with high-speed imaging, we study the filaments and their extensional response during deformation. Ex situ small-angle X-ray scattering (SAXS) reveals the morphology of the filaments after the cessation of the flow. In addition, we attempt to model the rheological response using the hypothesis that a nucleating melt behaves like a cross-linked network.

\section{MATERIALS AND METHODS}

We investigated a commercial HDPE (CP00416-021 from Chevron Philips), referred to as "PE-460k" with 0.2 shortchain branches/1000 backbone carbons. The molecular weight distribution was characterized in a Polymer Laboratories GPC220 instrument with $2 \times 30 \mathrm{~cm}$ PlOlexis columns and a PlOlexis guard column operated at $160^{\circ} \mathrm{C}$ with $1,2,4$ trichlorobenzene as eluent and $200 \mathrm{ppm}$ butylated hydroxytoluene as antioxidant. The measurements are shown in Fig. 1(A), from which $M_{w}=460 \mathrm{~kg} / \mathrm{mol}$ and PDI $=2.7$ were determined. (Note: The values of $M_{w}$ and PDI given by the supplier were slightly higher at $530 \mathrm{~kg} / \mathrm{mol}$ and 3.0, respectively.)

Differential scanning calorimetry (DSC) measurements were performed on a Discovery DSC from TA Instruments in a nitrogen atmosphere with heating and cooling rates of $10^{\circ}$ $\mathrm{min}^{-1}$ from 50 to $200^{\circ} \mathrm{C}$. The samples weighed approximately $2-5 \mathrm{mg}$. The melting temperature of $138.0^{\circ} \mathrm{C}$ was obtained from an endothermic peak in the second heating process.

Samples for all rheological characterizations were molded into disks of diameter $8-9 \mathrm{~mm}$ and height $2.5 \mathrm{~mm}$. Molding was carried out either in a hot press $\left(165^{\circ} \mathrm{C}, 30 \mathrm{~min}\right)$ or a vacuum mold $\left(150^{\circ} \mathrm{C}, 15 \mathrm{~min}\right)$. These conditions were found sufficient for erasing the thermomechanical history as annealing for longer (up to $48 \mathrm{~h}$ ) in a vacuum oven at $160{ }^{\circ} \mathrm{C}$ or in the rheometer at $150^{\circ} \mathrm{C}$ did not change the results (i.e., fracture, rheology, or FIC).

The linear rheology was characterized in small angle oscillatory shear (SAOS) using an Ares G2 (TA Instruments) with $8 \mathrm{~mm}$ parallel plate geometry and creep using an MCR702 (Anton Paar). The creep data obtained at $150{ }^{\circ} \mathrm{C}$ were inverted initially to storage and loss compliance [18] and then to storage and loss moduli as described by Wingstrand et al. [19] (see also Münstedt and coworkers $[20,21])$. Inverted creep data and the frequency sweeps from SAOS obtained at $140-190^{\circ} \mathrm{C}$ were combined using the time temperature superposition principle (TTS) to obtain master curves of dynamic moduli over a wide range of frequencies. Because of the very high molecular weight tail, the terminal regime at which $G^{\prime}$ and $G^{\prime \prime}$ reach a slope of 2 and 1, respectively, was inaccessible experimentally, even in creep. In fact, the shoulder at low frequencies appears consistent with a tail of about $5.000 \mathrm{~kg} / \mathrm{mol}$ and the 3.4 scaling law, starting from the crossover, which is assigned to be $530 \mathrm{~kg} / \mathrm{mol}$. The horizontal shift factors $a_{T}$ and an Arrhenius fit are shown in the inset of Fig. 1(B). The linear response was fitted by a multimode Maxwell model

$$
G(s)=\sum_{i} g_{i} \exp \left(-s / \tau_{i}\right) .
$$
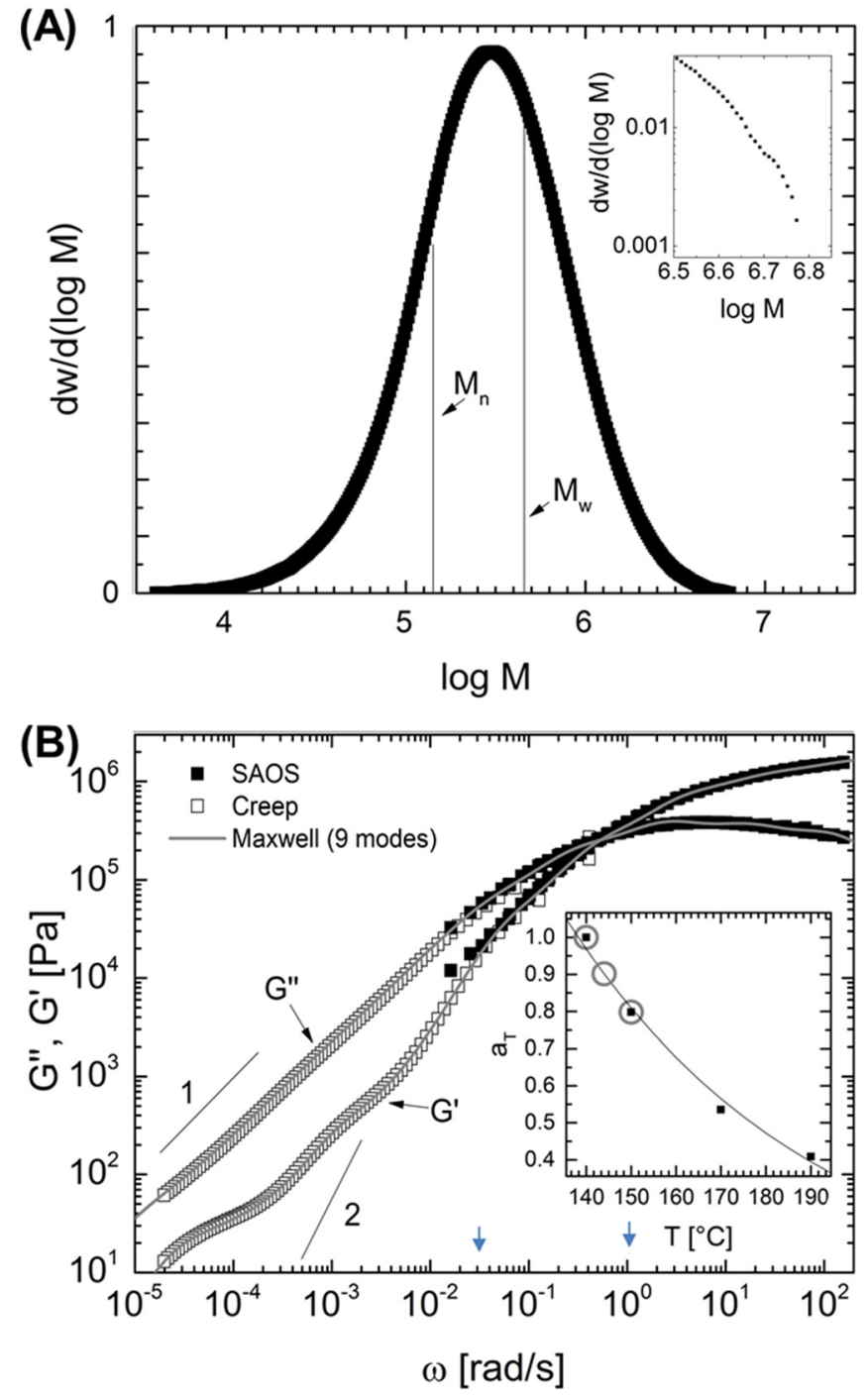

FIG. 1. Initial characterization of PE-460k: (A) molecular weight distribution. Vertical black lines indicate number average molar mass $M_{n}$ and weight average molar mass $M_{w}$. The inset shows a magnification of the highest molecular weight fraction on a logarithmic vertical scale, whereby a shoulder in the molar mass distribution becomes apparent around $\log$ $M \approx 6.7$. (B) Linear rheology represented in terms of storage modulus $G^{\prime}$ and loss modulus $G^{\prime \prime}$ of PE-460k at reference $T_{0}=140^{\circ} \mathrm{C}$. Closed symbols indicate data obtained via SAOS, and open symbols indicate data obtained via creep. Gray lines show the fit of the multimode Maxwell model. The blue arrows indicate the range of strain rates in the extensional flow experiments. The inset shows the horizontal shift factors obtained from SAOS (black squares), along with the Arrhenius prediction (black line) at the reference temperature $T_{0}=140^{\circ} \mathrm{C}$. Gray circles indicate the temperatures at which extensional measurements were performed and the corresponding shift factors used for adjusting the Hencky strain rates.

The moduli $g_{i}$ and time constants $\tau_{i}$ of the nine modes are given in Table I [see also Fig. 1(B)].

We conducted uniaxial extensional experiments at constant Hencky strain rates $\dot{\varepsilon}$. The instrument used was a filament stretch type rheometer (VADER 1000 from RheoFilament). It allows for on-line control of the true Hencky strain given by $\varepsilon=-2 \ln \left(D / D_{0}\right)$, where $D$ and $D_{0}$ are the current and initial diameter, respectively [22-25]. The true stress of the material during deformation is in its simplest form given by $\sigma_{z z}-\sigma_{r r}$ $=(F-(1 / 2) m g) /\left((\pi / 4) D^{2}\right)$, where $\mathrm{F}$ is the measured axial force, $m$ is the mass of the filament, and $\mathrm{g}$ is the gravitational 
TABLE I. Multimode Maxwell parameters for PE-460k at $T=140^{\circ} \mathrm{C}$.

\begin{tabular}{lcc}
\hline \hline Mode, $\mathrm{i}$ & $\tau_{\mathrm{i}}(\mathrm{s})$ & $\mathrm{g}_{\mathrm{i}}(\mathrm{Pa})$ \\
\hline 9 & $4.63 \times 10^{4}$ & $2.73 \times 10$ \\
8 & $6.63 \times 10^{3}$ & $1.77 \times 10$ \\
7 & $9.48 \times 10^{2}$ & $3.86 \times 10^{2}$ \\
6 & $1.36 \times 10^{2}$ & $6.61 \times 10^{2}$ \\
5 & $1.94 \times 10$ & $5.16 \times 10^{4}$ \\
4 & 2.78 & $2.58 \times 10^{5}$ \\
3 & $3.98 \times 10^{-1}$ & $5.65 \times 10^{5}$ \\
2 & $5.69 \times 10^{-2}$ & $4.56 \times 10^{5}$ \\
1 & $8.14 \times 10^{-3}$ & $4.42 \times 10^{5}$ \\
\hline \hline
\end{tabular}

acceleration. The correction for initial shearing contribution is described elsewhere [26]. The experiments were performed at three different temperatures $\left(140,144\right.$, and $\left.150^{\circ} \mathrm{C}\right)$ and terminated by quenching to room temperature at a Hencky strain $\varepsilon=5$. We used shift factors determined from SAOS [see the inset in Fig. 1(B)] to adjust the Hencky strain rates such that all samples were stretched at the same relative rates $a_{T} \dot{\varepsilon}$ irrespective of temperature. For selected samples, the filament deformation was recorded using a high speed camera (FASTCAM Mini UX100 from Photron) with a light-emitting diode light source placed either on the same side or opposite the camera.

Small angle X-ray scattering (SAXS) of the quenched filaments was performed using a Rigaku S-MAX 3000 system with a Gabriel design Multiwire, gas-filled proportional type detector (resolution: $200 \mu \mathrm{m}$ ). The sample-to-detector distance was $1525 \mathrm{~mm}$, and the exposure time for each pattern was $15-30 \mathrm{~min}$. Patterns were collected from the midfilament plane of the samples.

\section{RESULTS AND DISCUSSION OF UNIAXIAL EXTENSION EXPERIMENTS}

Figure 2 shows the rheological response of PE-460k in uniaxial extensional flow at three different temperatures: 140,144 , and $150^{\circ} \mathrm{C}$. The results are given in terms of

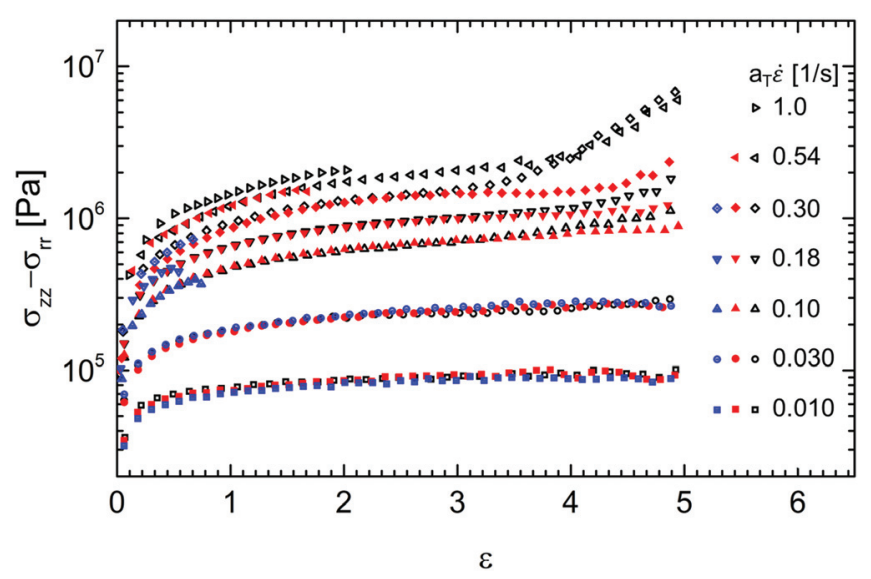

FIG. 2. Response of PE-460k in uniaxial extension at $T=140^{\circ} \mathrm{C}$ (black symbols), $T=144^{\circ} \mathrm{C}$ (red symbols), and $\mathrm{T}=150^{\circ} \mathrm{C}$ (blue symbols). When possible extensional flow experiments were terminated at $\varepsilon=5$ and quenched to room temperature. Due to filament fracture, some experiments terminate earlier than $\varepsilon=5$. extensional stress versus Hencky strain at the same values of $a_{T} \dot{\varepsilon}$ which eliminates further need for TTS shifting. At low deformation rates $\left(a_{T} \dot{\varepsilon}=0.01\right.$ and $\left.0.03 \mathrm{~s}^{-1}\right)$, the start-up responses at all three temperatures overlap, including the apparent steady flow condition reached at $\varepsilon \geq 4$. The overlap implies that the nature of the response is independent of temperature and, therefore, that TTS applies at low deformation rates. At high deformation rates $a_{T} \dot{\varepsilon} \geq 0.1 \mathrm{~s}^{-1}$, TTS breaks down, and the response becomes highly temperature dependent. At $150^{\circ} \mathrm{C}$, the sample undergoes brittle fracture at strains $\varepsilon<1$. At 140 and $144^{\circ} \mathrm{C}$, PE-460k can be stretched beyond $\varepsilon=1$ without undergoing fracture, but the rheological response at the two temperatures differs. The strain hardening at $140^{\circ} \mathrm{C}$ is significantly more pronounced than at $144^{\circ} \mathrm{C}$. As the response of PE-460k at 140 and $144^{\circ} \mathrm{C}$ does not overlap for $a_{T} \dot{\varepsilon} \geq 0.1 \mathrm{~s}^{-1}$, TTS do not apply in this region. The break-down of TTS indicates that a flow induced phenomenon occurs with a characteristic time that does not scale with regular chain dynamics. We argue in the following, that the phenomenon in question is flow induced crystallization (FIC) that furthermore reinforces the filament and prevents fracture.

The observations from Fig. 2 can be grouped into three regimes as illustrated in Fig. 4. (1) The TTS-regime where the response is independent of temperature, (2) the fracture regime in which stretching to $\varepsilon=5$ is impossible due to failure of the filament, and (3) the FIC-regime where strain hardening due to FIC prevents the filament from fracturing.

Figures 3(A) and 3(B) show the difference between stretch experiments performed within FIC and fractureregimes, respectively. Figure 3(B) shows a wedgelike edge fracture that separates the filament into two parts with flat surfaces as shown in the inset. By contrast, in the FICregime [Fig. 3(A)], the filament remains intact with a smooth surface throughout the entire stretch. In the following, the two regimes will be analyzed in more detail.

\section{A. The fracture regime}

This section solely focuses on the fracture regime from Fig. 4 where all stretch experiments results in brittle fracture. Figure 5 shows time resolved images of the filament during fracture. Multiple cracks propagate simultaneously [16] and influence the profiles of adjacent cracks. We use the early stages of the crack propagation, where the profile is less perturbed by adjacent cracks, to further analyze the fracture mechanics.

Time-resolved images similar to those shown in Fig. 5 allow us to plot the crack opening at several different times in a common coordinate system as shown in Fig. 6(A). Here, $0 \mathrm{~ms}$ arbitrarily indicates the time for the first clear detection of a crack profile, $29 \mathrm{~ms}$ indicates the surface $29 \mathrm{~ms}$ later, and so on. For each time, the coordinate system is shifted to have origin at the cracktip with the $x$-axis pointing in the direction opposite of the crack movement. The profiles plotted in Fig. 6(A) are collected from a fracture that, relative to Fig. 5, was less influenced by adjacent cracks. Despite a considerable amount of scattering, the crack openings may be reasonably well fitted by a parabola, as indicated by the thin 

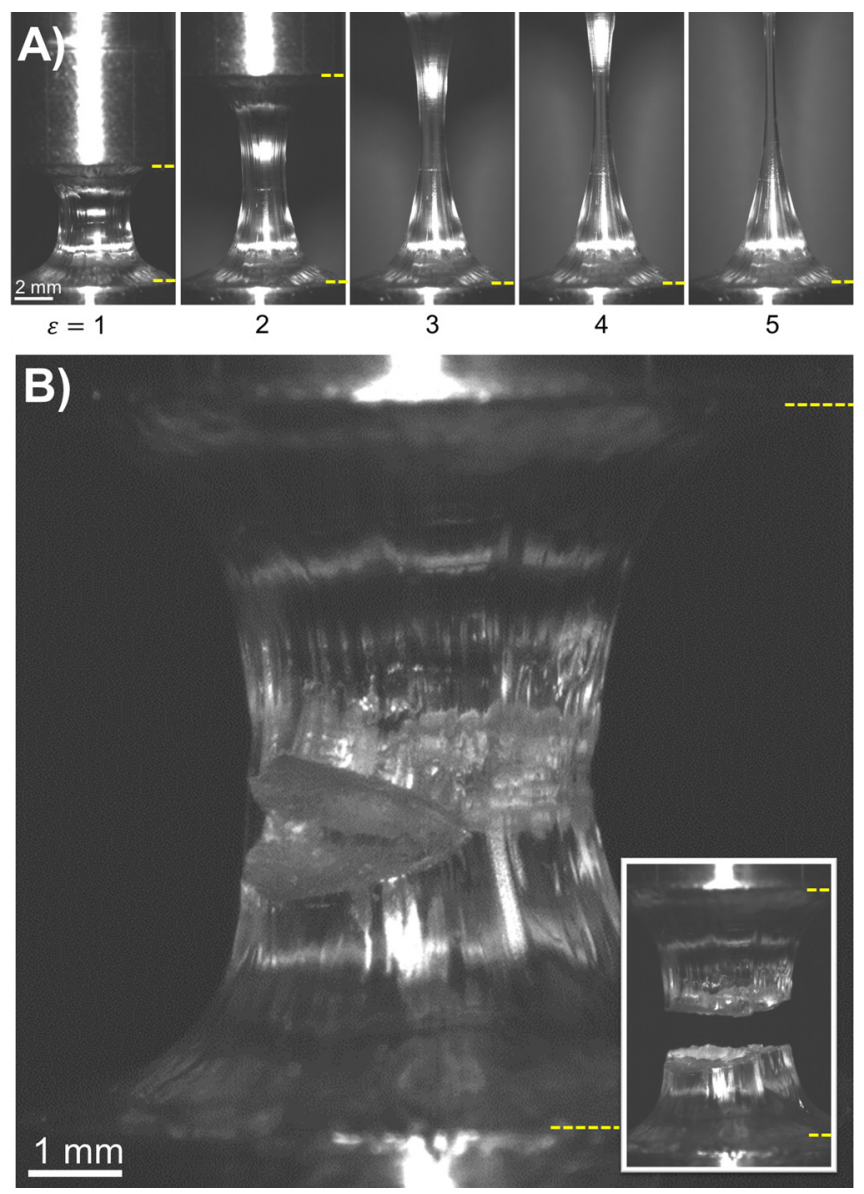

FIG. 3. Images of PE-460k in elongational flow stretched at $a_{T} \dot{\varepsilon}=0.18 \mathrm{~s}^{-1}$. (A) At $T=140{ }^{\circ} \mathrm{C}$ and (B) at $T=150^{\circ} \mathrm{C}$. The inset shows the filament after fracture. All images are obtained with camera and light source on the same side. Bright spots on the filament and the top plate surface are reflections from the light source. The yellow dashed lines indicate vertical positions of sample-plate boundaries.

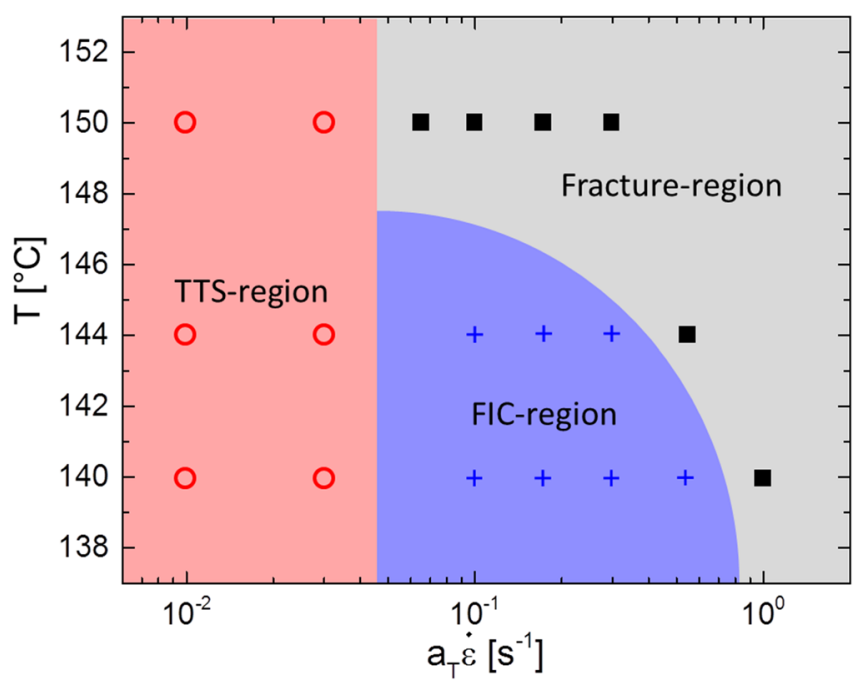

FIG. 4. Diagram delineating three types of dynamic behavior of PE-460k in uniaxial extension for combinations of reduced stretch rate (abscissa) and temperature in centigrade (ordinate): The TTS-region where the melt satisfies the time-TTS, the fracture-region where the melt fractures before reaching $\varepsilon=5$, and the FIC-region where FIC occurs and prevents the filament from fracturing. solid line. Moreover, the analysis allows determination of the deformation rates as a function of the distance from the crack tip estimated roughly as $\dot{\gamma} \sim V d^{2} u / d x^{2}$. An example is shown by the dotted line in Fig. 6(A) which illustrates that the deformation rates increase strongly as the crack tip is approached. The present linear elastic analysis breaks down at the crack tip, where a singularity is predicted. The deformation rates calculated for most of the observed regime are in the range of 1 to about $10^{2} \mathrm{~s}^{-1}$.

Figure 7 summarizes the critical fracture strains and stresses. Since the strains at fracture are all below one Hencky strain unit, we may compare the deformation rates from Fig. 6(A) with the linear viscoelastic spectrum in Fig. 1. For $0.5 \mathrm{rad} / \mathrm{s}<\omega<10^{2} \mathrm{rad} / \mathrm{s}$, the loss tangent $\tan \delta$ $=G^{\prime \prime} / G^{\prime} \leq 1$, indicating primarily solid like behavior. This is in agreement with the parabolic trend [27] in Fig. 6(A).

It remains to rationalize the crack velocity. For an incompressible purely elastic material, the crack velocity is limited by the speed of the shear wave $v_{s}=\sqrt{G / \rho}$, where $G$ is the shear modulus $[27,28]$. For a viscoelastic liquid, the corresponding expression is $v_{s}=\sqrt{G^{\prime} / \rho}\left(1+(3 / 8) \tan ^{2} \delta+\cdots\right)$ ([29], the ratio $\omega / \beta$ in Example 5.4-1 expanded for small $\tan \delta$ ), so a small amount of dissipation does not materially alter the shear wave velocity. Since both expressions give shear wave speeds orders of magnitude greater than the measured crack velocity (of order $1 \mathrm{~mm} / \mathrm{s}$ ), we conclude that inertia is not the limiting effect for the crack speed. Even with the parabolic trend in Fig. 6(A), we suggest, therefore, that dissipation is an important effect in the fracture process. For a single mode, Maxwell model of time constant $\tau$ de Gennes [30] suggests that the parabolic crack profile close to the crack tip opens up in a trumpetlike profile for distances larger than $v_{s} \tau$. While the present PE-460k is far from a single mode material, one might argue that the dissipation is visible by the small tendency to a trumpetlike opening of the crack profile [16,17] for distances more than about $0.2 \mathrm{~mm}$. Thus, we arrive at a fracture regime with primarily elastic edge fractures albeit with crack speeds influenced by dissipation.

\section{B. The FIC-regime}

This section focuses on the FIC-regime from Fig. 4. In this regime, brittle fracture is believed to be suppressed by reinforcement of the filament due to FIC even though experiments are carried out above $T_{m}$. Previous studies have shown that FIC in polyethylene subjected to strong flows is indeed possible above $T_{m}$ [31-33] due to a flow induced transition from the folded chain crystals that make up spherulites and kebabs to the considerably more stable extended chain crystals found in shish having a higher $T_{m}$.

Evidence of FIC during flow is present both in the nonlinear extensional rheology and ex situ scattering patterns. The signs of FIC in the extensional rheology (Fig. 2) are first of all the absence of steady flow for stretch experiments within the FIC-region. Second, for experiments conducted at $140^{\circ} \mathrm{C}$ at the highest rates $\left(a_{T} \dot{\varepsilon}=0.3\right.$ and $\left.0.54 \mathrm{~s}^{-1}\right)$, a rateindependent response is observed at $\varepsilon>4$. Third, break down of TTS. The first two characteristics suggest that the 

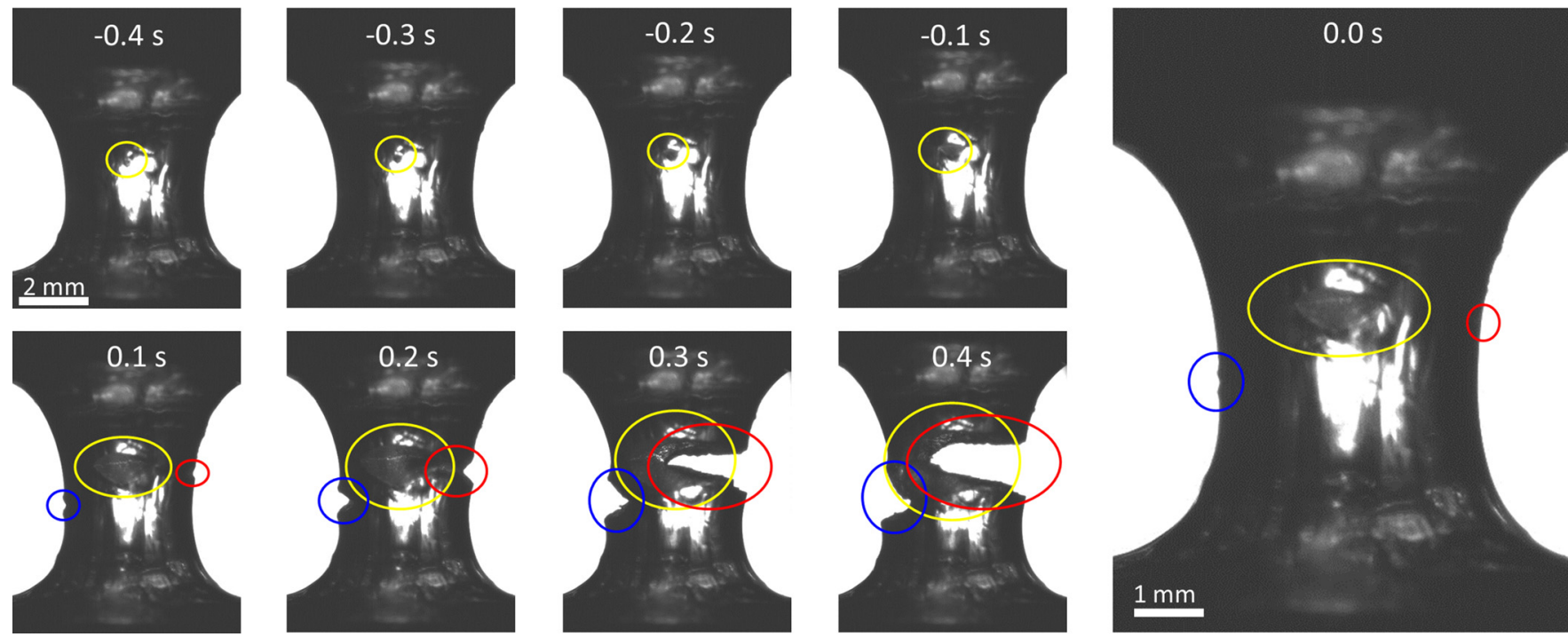

FIG. 5. Development of multiple cracks in the midfilament region for PE-460k stretched at $a_{T} \dot{\varepsilon}=0.18 \mathrm{~s}^{-1}$ and $T=150{ }^{\circ} \mathrm{C}$. The ellipses indicate regions where cracks are developing. $t=0 \mathrm{~s}$ is defined as the time at which the crack indicated by the blue circle is initiated.

sample undergoes a liquidlike to a solidlike transition as would be expected from a crystallizing melt. The last characteristic suggests that the characteristic time scale for the structural change within the melt is different from that of Gaussian chain dynamics as would be expected for FIC. Signs of FIC can be found in the ex situ SAXS patterns (Fig. 8) obtained from quenched filaments after cessation of flow as well. The SAXS-patterns are characterized by meridional lobes and an equatorial streak signifying scattering from kebabs and shishes, respectively. We assume that kebabs only form after cessation of flow and quench below $T_{m}$, so
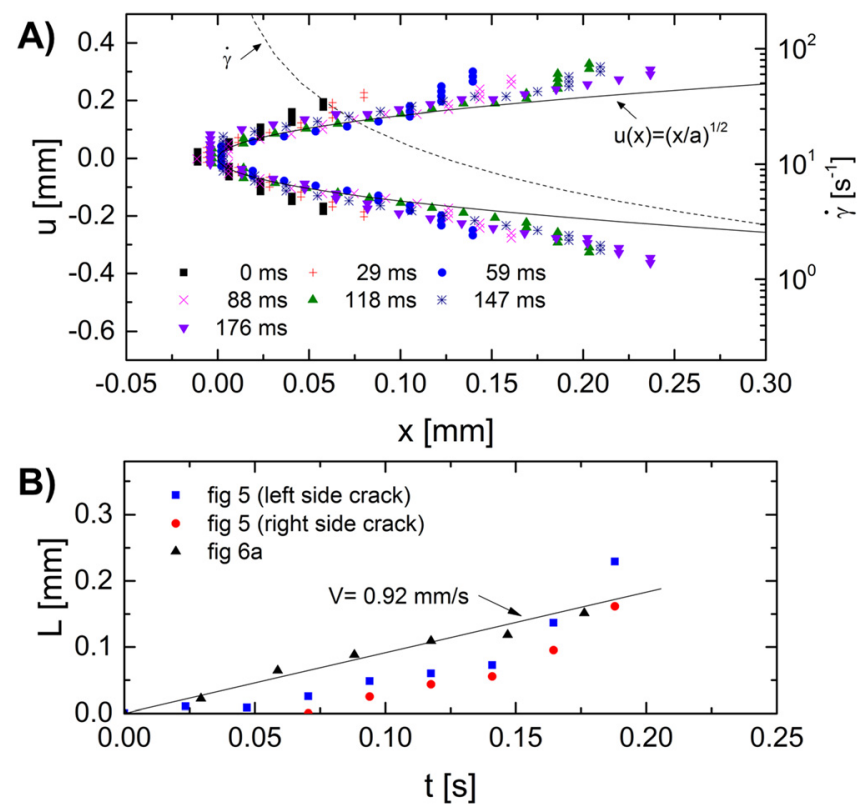

FIG. 6. Fracture analysis for PE-460k stretched at $a_{T} \dot{\varepsilon}=0.18 \mathrm{~s}^{-1}$ and $T=150^{\circ} \mathrm{C}$. (A) Fracture profiles showing the initial development of the crack propagation. (B) Crack length for three cracks. Circular dots and solid squares correspond to crack lengths observed for the cracks on the right and left side of the filament, respectively, in Fig. 5. Black symbols show the crack length for the fracture in (A) with black line being the best linear fit yielding a crack tip velocity of $V=0.92 \mathrm{~mm} / \mathrm{s}$. that nucleation and growth of shishes are the only structures forming during elongation. Consequently, we focus on the equatorial streak evolution in relation to justifying the presence of FIC. Evidently, the equatorial streak is present only in the FIC-region. This is a clear indication that the observed solidlike behavior and break down of TTS indeed is caused by FIC. The streak intensifies for increasing deformation rates suggesting an increased concentration of shish [34]. This is in agreement with previous studies attributing the number of flow-induced shish nuclei to the degree of chain stretch that increases with the deformation rate [35].

Scattering from the kebabs points to the overall stretch of the melt, in this study, at the point of quench [36]. The greater the intensification along the meridional, the greater the alignment of kebabs perpendicular to the flow direction and the greater the average chain stretch at the point of quench. To quantify the anisotropy, Hermans orientation

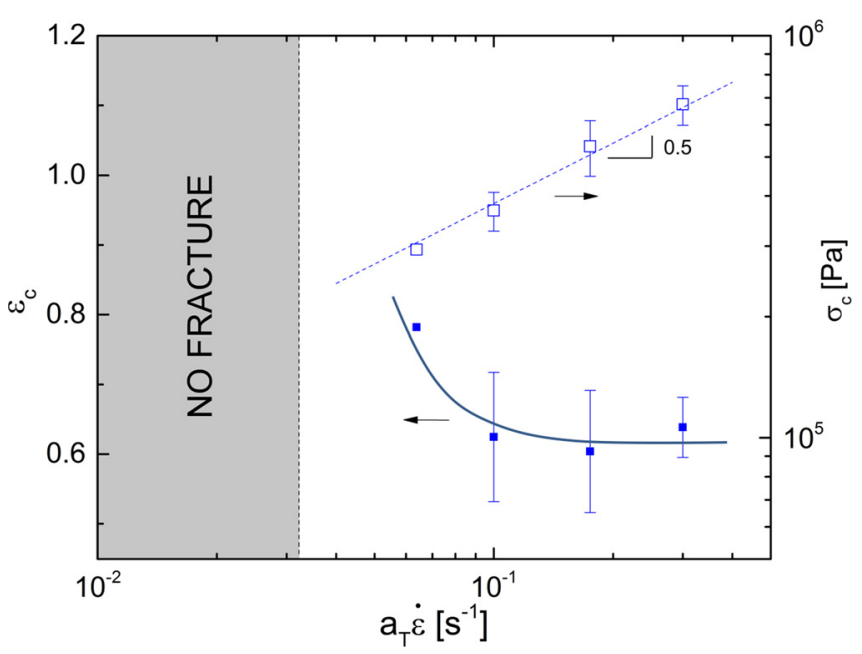

FIG. 7. Critical fracture strain (closed symbols) and critical fracture stress (open symbols) for PE-460k at $T=150^{\circ} \mathrm{C}$. Solid and dashed lines are guides to the eye, indicating a plausible evolution of critical stress and strain. The arrows indicate the corresponding axes. 


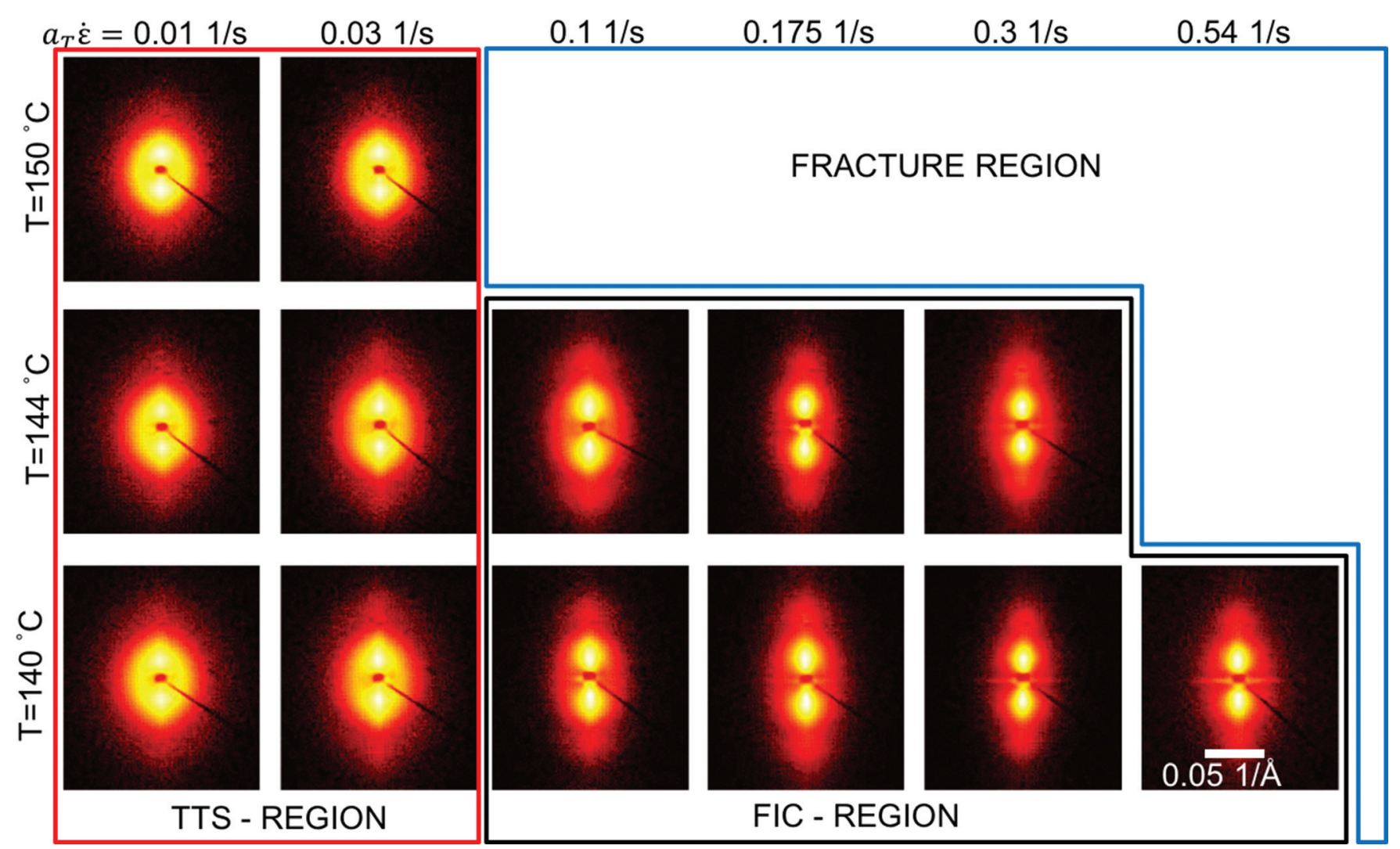

FIG. 8. SAXS patterns of PE-460k filaments at room temperature after uniaxial stretch above $T_{m}$ and quench at $\varepsilon=5$. The stretching direction is vertical. The red, blue, and black outlines indicate the boundaries for the TTS-region, the FIC-region, and the fracture-region.

factor is extracted from the SAXS patterns according to procedures described in a previous publication [19]. The only difference being the use of a Gaussian distribution instead of a Lorentzian distribution to fit the azimuthal intensity peaks. Hermans orientation factor $F_{H}$ is given by

$$
F_{H}=\frac{3\left\langle\cos ^{2} \phi\right\rangle-1}{2}
$$

where $\left\langle\cos ^{2} \phi\right\rangle$ is the average cosine squared of the angle $\phi$ given as the angle between the normal of a plane in the crystalline domains and a given macroscopic direction. We determine $F_{H}$ from SAXS patterns using scattering between kebabs growing perpendicular to the shish aligned along the flow direction. $\phi$ is defined as the angle between the normal of the kebab-planes and the macroscopic direction set to be the stretching direction [37]. For perfect orientation of kebabs perpendicular to the flow direction $F_{H}=1$, whereas isotropic samples yields $F_{H}=0$.

Figure 9 shows $F_{H}$ versus the stress at quench. Previous studies on polyethylene in uniaxial extension in the absence of FIC (i.e., crystallization occurred only after cessation of flow) have found a one-to-one relation between $F_{H}$ and stress at quench $[19,24]$. This relation appears to hold for PE-460k as well, despite the presence of FIC. The orientation for all filaments, irrespective of the temperature during stretching, falls onto the same master curve. The master curve seems to have two regions. (1) A region in which $F_{H}$ follows a power law with an exponent of $2 / 5$, as observed in previous studies and (2) a plateau where the orientation saturates and stays constant around $F_{H} \sim 0.7$. The maximum theoretical value of Herman's orientation factor $F_{H, \max }=1$ (perfect unidirectional orientation). Thus, $F_{H}$ cannot keep increasing and a plateau region in which $F_{H, \max }=1$ is expected for the ideal case. Polymers are far from ideal. In fact, for PE-460k, the maximum orientation factor appears to be around 0.7 .

\section{MODELING EXTENSIONAL RHEOLOGY}

We use the hierarchical multimode stress function (HMMSF) formulated by Narimissa and Wagner as a base for modeling the nonlinear extensional behavior of PE-460k $[38,39]$. Any other nonlinear models using a discrete spectrum of relaxation times, e.g., the Rolie-Poly, could be used as well [40].

The HMMSF model calculates the total stress tensor $\boldsymbol{\sigma}$ as a sum of stress contributions $\boldsymbol{\sigma}_{i}$ from each Maxwell mode

$$
\boldsymbol{\sigma}=\sum_{i} \boldsymbol{\sigma}_{i}
$$

where $\sigma_{i}$ is given by

$$
\boldsymbol{\sigma}_{i}(t)=-\frac{g_{i}}{\tau_{i}} \int_{-\infty}^{t} e^{-\left(t-t^{\prime}\right) / \tau_{i}} \mathbf{S}_{D E}^{I A}\left(t, t^{\prime}\right) f_{i}^{2}\left(t, t^{\prime}\right) d t^{\prime}
$$

Here, $\mathbf{S}_{D E}^{I A}$ is the Doi-Edwards orientation tensor using the independent alignment approximation [41-43], and $f_{i}$ 


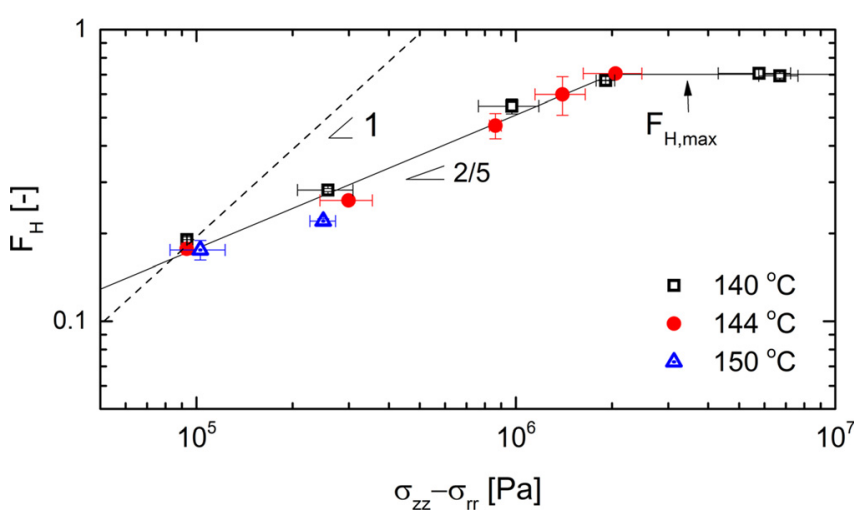

FIG. 9. Herman's orientation in quenched filaments versus the stress at quench. Symbols indicate filaments stretched at $140^{\circ} \mathrm{C}$ (squares), $144^{\circ} \mathrm{C}$ (circular dots), and $150^{\circ} \mathrm{C}$ (triangles). The solid line is a guide to the eye showing two regions: One with a slope of $2 / 5$ followed by a plateau region. The dashed line shows the linear relation observed in amorphous systems.

is the segmental chain stretch of mode $i$. Detailed descriptions of the model along with definition of $\mathbf{S}_{D E}^{I A}$ and $f_{i}$ can be found elsewhere [19,38]. The HMMSF model contains one fitting parameter $G_{D}$, the dynamic dilution modulus. It is a point along the relaxation modulus that separates permanently diluted chain segments from dynamically diluted chain segments.

Figure 10 shows the HMMSF prediction using $G_{D}$ $=600 \mathrm{~Pa}$ and the Multimode Maxwell spectrum given in Table I compared with the experimental data. At $\varepsilon<3$, the measured response is relatively well captured by the HMMSF model for all deformation rates. However, as the model does not consider FIC, it does not capture the strain hardening due to FIC observed at $\varepsilon>3$ for experiments conducted in the FIC regime (i.e., $a_{T} \dot{\varepsilon} \geq 0.1$ ). Several studies use the onset of discrepancy between the nonlinear model and data to define the onset of crystallization $[33,44]$. In Sec. IV B below, we propose an alternative and in our opinion more accurate way to detect the onset of crystallization.

\section{A. Incorporating FIC into the HMMSF model}

In this section, we incorporate the effect of crystallization into the HMMSF model. Several approaches to modeling

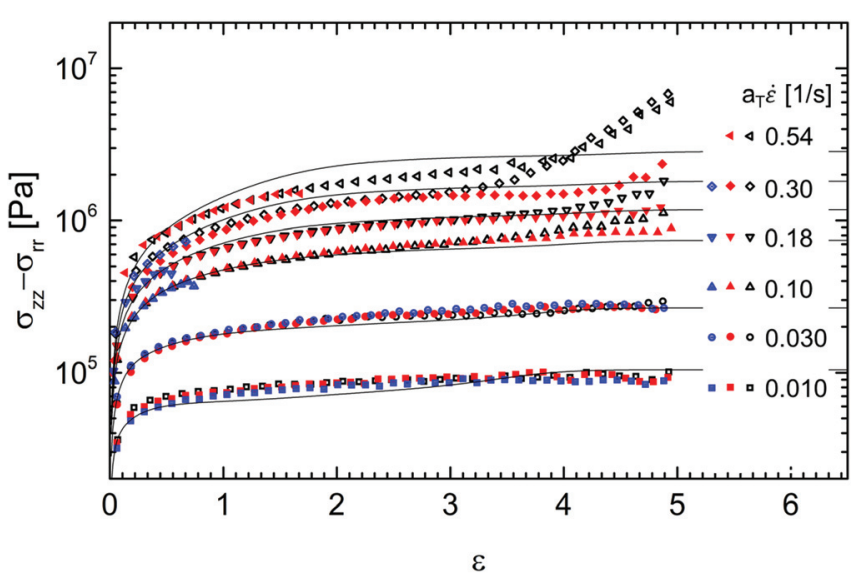

FIG. 10. Comparison of the measured extensional stress (symbols) and HMMSF-predicted extensional stress (lines) of PE-460k. The value of nonlinear fit parameter $G_{D}=600 \mathrm{~Pa}$ and nine Maxwell modes are used in the modeling of the stretch experiments. Black, red, and blue symbols indicate stretch experiments performed at $T=140, T=144$, and $T=150^{\circ} \mathrm{C}$, respectively.

FIC exist [45-48]. In this study, we consider the nucleating melt as a stretched network as illustrated in Fig. 11 where we use the nondimensional extension rate $W i_{R}=\dot{\epsilon} \tau_{R}$ based on the time constant for molecular stretch relaxation $\tau_{R}$. Crystalline nuclei are assumed to trap several chain segments in a nucleus and thus effectively act as a cross-link. The idea was originally introduced by Penning and coworker [49], and in recent years, experimental studies [8-11,50,51] seem to prefer the stretched network idea over the coil-stretch transition proposed by Keller and Kolnar [4].

We incorporate the stretched network assumption into the HMMSF model by modifying the relaxation time spectrum - not the model itself. If only a few nuclei exist, effectively the melt is weakly cross-linked, and therefore, only the slowest modes are affected. If the density of nuclei is high, the relaxation of faster modes is affected as well. The modes affected by cross-links are set to have a relaxation time $\tau_{i}=\infty$. In the following, these modes are referred to as locked modes. Modes with a finite relaxation time are referred to as free modes. The modes are hierarchically locked meaning that a fast mode $i$ cannot lock unless all
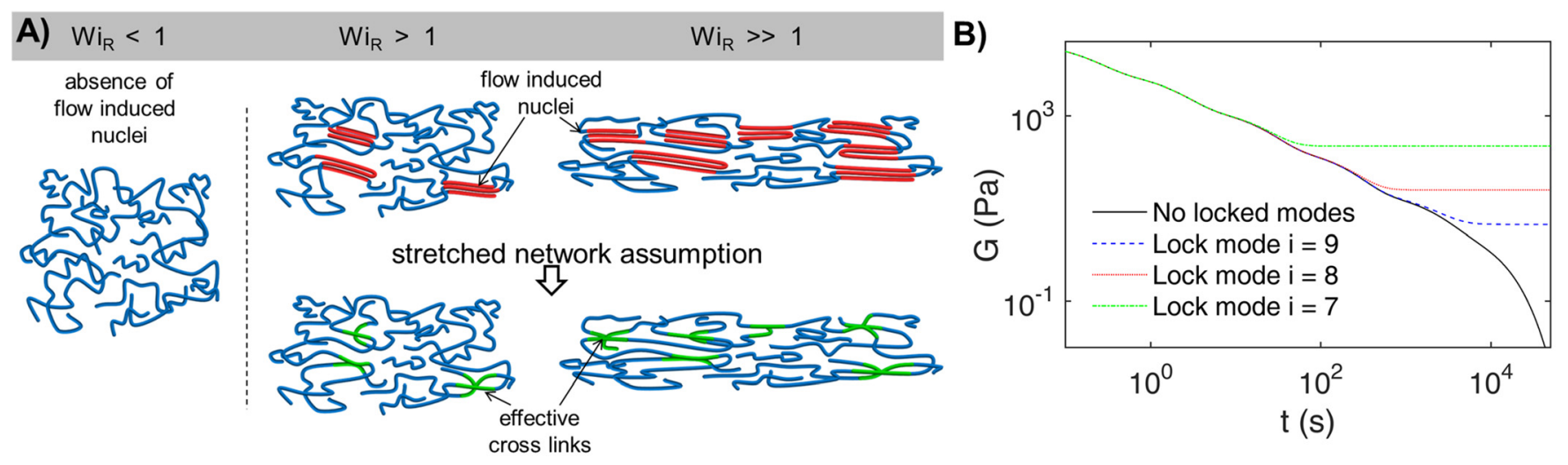

FIG. 11. Stretched network assumption principle and effect on relaxation modulus. (A) Illustration of the principle behind the stretched network assumption during uniaxial deformation and the effect. The top row shows flow induced nuclei imbedded in an amorphous polymer matrix going from low $W i_{R}$ (left) to high $W i_{R}$ (right). The bottom row shows how the effect of flow induced nuclei is modeled by substituting flow induced nuclei with effective cross-links. The flow direction is horizontal. (B) The effect of locking modes on the relaxation modulus. A lock mode $\mathrm{i}=7$ means that the 7 th -9 th modes have $\tau_{i}=\infty$. 
modes slower than $i$ are locked as well. The effect of locking modes on the relaxation modulus is illustrated in Fig. 11(B). We assume that the crosslinking density is constant throughout the stretch, and hence, that the number of locked modes during a given stretch is constant. The model as implemented here assumes that very fast modes are not affected by crystallization. Of course, this is not totally correct because when the nuclei are formed, also a lot of long and short dangling chains are formed. The motion of such dangling chains would also contribute to change the spectrum in the region of the faster modes. In fact, the number of locked modes also serves as a fitting parameter which could be eliminated by incorporating a kinetic model for FIC. In addition, we neglect latent heat released by crystallization, changes in density caused by crystallization, and any influence from the spatial size of the nuclei. These assumptions are expected to be valid only during the initial stage of crystallization, when the sizes of crystalline domains are small, and hence, the degree of crystallinity was limited.

Figures 12(A) and 12(B) show the results of the modeling for 140 and $144^{\circ} \mathrm{C}$, respectively. This approach, indeed, enables the influence of shish formation on the extensional rheology to be captured. Note, in particular, that at $140{ }^{\circ} \mathrm{C}$ and $a_{T} \dot{\varepsilon} \geq 0.3$, the stress becomes independent of the stretch rate
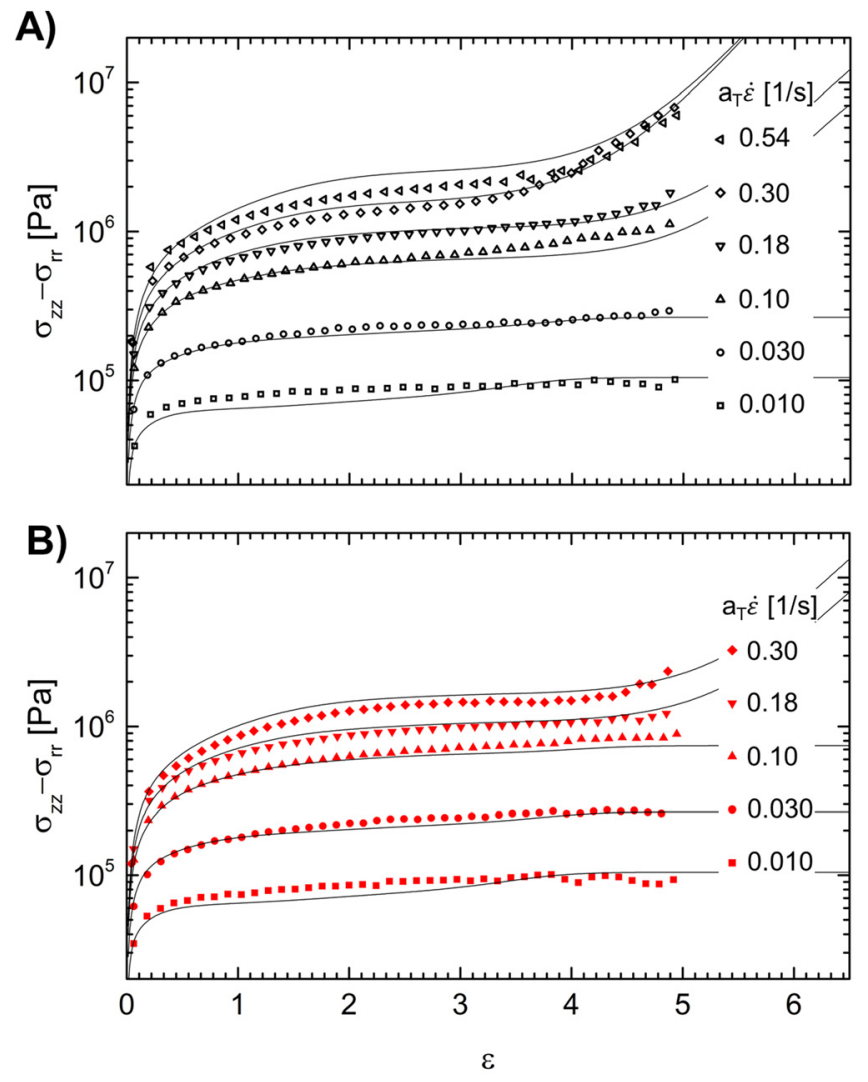

FIG. 12. Comparison of the measured extensional stress (symbols) and HMMSF predicted extensional stress using locked modes (lines) of PE-460k (A) at $T=140^{\circ} \mathrm{C}$ and (B) $T=144^{\circ} \mathrm{C}$. The value of nonlinear fit parameter $G_{D}=600 \mathrm{~Pa}$ and nine Maxwell modes are used in the modeling. Depending on the stretch rate $a_{T}{ }^{*}[1 / \mathrm{s}]$ the following modes are locked: For $(\mathrm{A}), 0.54$ and 0.30: modes 7-9; 0.18: modes 8 and 9; 0.10: mode 9; and 0.030 and 0.010: no locked modes. For (B), 0.30: modes 8 and 9; 0.18: mode 9; and 0.10, 0.030, and 0.010: no locked modes. A locked mode $i$ has $\tau_{i}=\infty$. once $\varepsilon \geq 4$. Even this behavior, normally associated with solids, is taken into account in the model.

\section{B. Considerations on the onset of FIC}

As previously mentioned, several studies use the onset of discrepancy between measured extensional response and the nonlinear model prediction without crystallization as the onset of crystallization $[33,44]$. To investigate if indeed this discrepancy is a sensitive indicator of the onset of FIC we compare in Fig. 13 the effect of locking modes versus leaving them free for $a_{T} \dot{\varepsilon}=0.3$ and $0.1 \mathrm{~s}^{-1}$, respectively. It shows that evidence of FIC in the rheology appears at $\varepsilon>3$
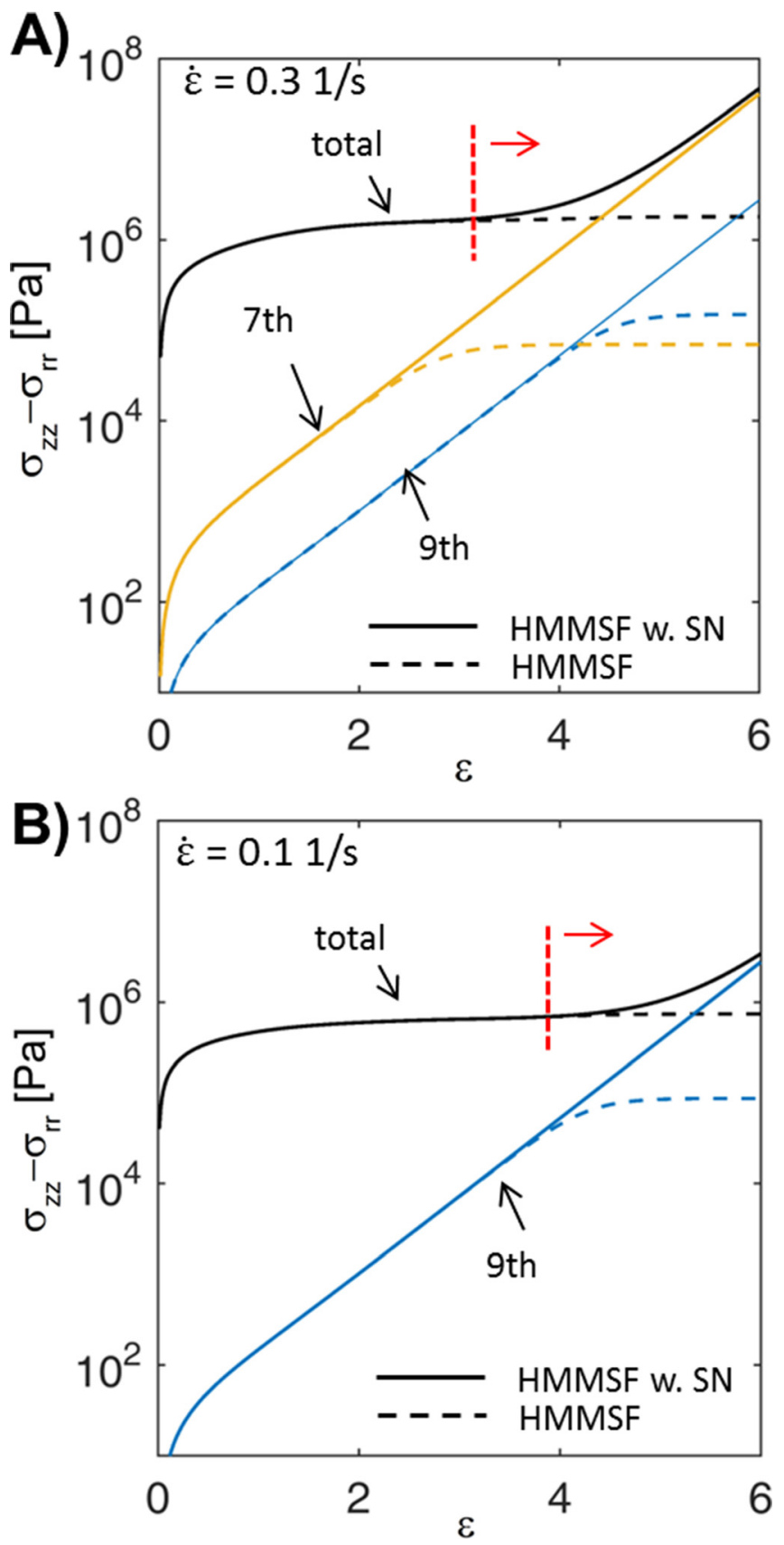

FIG. 13. Comparison of the basic HMMSF model (dashed lines) and the HMMSF model, including stretched network (solid lines). Full lines indicate total stress and contributions from selected modes. (A) For $a_{T} \dot{\varepsilon}=0.3 \mathrm{~s}^{-1}$ and (B) for $a_{T} \dot{\varepsilon}=0.3 \mathrm{~s}^{-1}$. Vertical red dashed lines indicate the point at which the total stress is influenced by FIC. 
(vertical dashed lines in Fig. 13). The onset of crystallization may nevertheless have occurred anywhere between $\varepsilon=0$ and 3. In fact, comparing experiments from the FIC-region with experiments conducted in the fracture region (Fig. 4) enables a more accurate determination of the onset of crystallization. We hypothesize that nucleation and growth of shish in the FIC-region (i.e., 140 and $144^{\circ} \mathrm{C}$ ) reinforce the filament and enable extensional flow without failure caused by brittle fracture. In order for FIC at a given $a_{T} \dot{\varepsilon}$ to prevent brittle fracture, the onset must occur prior to the fracture strain observed in the fracture region for the same $a_{T} \dot{\varepsilon}$. The fracture strain for $a_{T} \dot{\varepsilon}=0.1-0.3 \mathrm{~s}^{-1}$ is $\approx 0.6$ for all rates at $150^{\circ} \mathrm{C}$. Consequently, the onset of crystallization at 140 and $144^{\circ} \mathrm{C}$ must have been between $\varepsilon=0$ and 0.6 . That is, assuming that the fracture mechanics is independent of temperature from 140 to $150{ }^{\circ} \mathrm{C}$. The new span of $\varepsilon$ for the onset of crystallization is much smaller than the one obtained from the rheology, and the values are surprisingly low. It suggests that initiation of shish nucleation does not require large deformations. A moderate deformation of only $\varepsilon=0.6$ is sufficient. This value is quite low compared to previously reported values $[8,33,44]$ as a result of a more sensitive approach in detecting the onset of crystallization.

\section{CONCLUSION}

We have shown that flow-induced shish nucleation and growth in uniaxial extension above $T_{m}$ can stabilize filaments and prevent true fracture. We find the critical strain for the onset of the shish formation to be $\leq 0.6$, which is quite low compared to previously reported values. We have shown that under the conditions tested here, the qualitative influence of crystallization on the extensional rheology can be captured by incorporating the stretched network assumption into the HMMSF model. The modeling suggests that while the locking of chains between nuclei is introduced at a low Hencky strain, the effect remains invisible to rheology until much higher Hencky strains. The number of locked modes is a fitting parameter. More work will be needed to arrive at a fully predictive model, including locking of the modes.

\section{ACKNOWLEDGMENTS}

The authors gratefully acknowledge Bo Shen and Professor Julie A. Kornfield at California Institute of Technology for providing the material. A special thanks goes to Professor Dimitris Vlassopoulos for numerous helpful suggestions and comments. They also thank Core Facilities in the College of Engineering at Drexel University for beam time. Finally, the authors thank the European Soft Matter Infrastructure (Grant No. 731019 EUSMI H2020INFRAIA-2016-2017) and Aage og Johanne Louis-Hansens Fond for financial support.

\section{References}

[1] Flory, P. J., "Thermodynamics of crystallization in high polymers. I. Crystallization induced by stretching," J. Chem. Phys. 15, 397-408 (1947).
[2] Janeschitz-Kriegl, H., Crystallization Modalities in Polymer Melt Processing: Fundamental Aspects of Structure Formation (Springer Vienna, Vienna, 2010).

[3] Housmans, J.-W., R. J. A. Steenbakkers, P. C. Rooze mond, G. W. M. Peters, and H. E. H. Meijer, "Saturation of pointlike nuclei and the transition to oriented structures in flow-induced crystallization of isotactic polypropylene," Macromolecules 42, 5728-5740 (2009).

[4] Keller, A., and H. W. H. Kolnaar, "Flow-induced orientation and structure formation," in Materials Science and Technology (VCH Verlagsgesellschaft mbH, Weinheim, 1997), Vol. 17, pp. 187-268.

[5] Yang, L., R. H. Somani, I. Sics, B. S. Hsiao, R. Kolb, H. Fruitwala, and C. Ong, "Shear-induced crystallization precursor studies in model polyethylene blends by in-situ rheo-SAXS and rheo-WAXD," Macromolecules 37, 4845-4859 (2004).

[6] Peters, G. W. M., L. Balzano, and R. J. A. Steenbakkers, Handbook of Polymer Crystallization, 1st ed. (Wiley, New Jersey, 2013). pp. 399-432.

[7] Kumaraswamy, G., R. K. Verma, J. A. Kornfield, F. Yeh, and B. S. Hsiao, "Shear-enhanced crystallization in isotactic polypropylene. In-Situ synchrotron SAXS and WAXD," Macromolecules 37, 9005-9017 (2004).

[8] Yan, T., B. Zhao, Y. Cong, Y. Fang, S. Cheng, L. Li, G. Pan, Z. Wang, X. Li, and F. Bian, "Critical strain for Shish-Kebab formation," Macromolecules 43, 602-605 (2010).

[9] Cui, K., L. Meng, N. Tian, W. Zhou, Y. Liu, Z. Wang, J. He, and L. $\mathrm{Li}$, "Self-acceleration of nucleation and formation of Shish in extension-induced crystallization with strain beyond fracture," Macromolecules 45, 5477-5486 (2012).

[10] Cui, K., Z. Ma, Z. Wang, Y. Ji, D. Liu, N. Huang, L. Chen, W. Zhang, and $\mathrm{L}$. Li, "Kinetic process of Shish formation: From stretched network to stabilized nuclei," Macromolecules 48, 5276-5285 (2015).

[11] Wang, Z., F. Su, Y. Ji, H. Yang, N. Tian, J. Chang, L. Meng, and L. Li, "Transition from chain- to crystal-network in extension induced crystallization of isotactic polypropylene,” J. Rheol. 61, 589-599 (2017).

[12] Schrauwen, B. A. G., L. C A V. Breemen, A. B. Spoelstra, L. E. Govaert, G. W. M. Peters, and H. E. H. Meijer, "Structure, deformation, and failure of flow-oriented semicrystalline polymers," Macromolecules 8618-8633 (2004).

[13] Fielding, S. M., "Criterion for extensional necking instability in polymeric fluids," Phys. Rev. Lett. 107, 258301 (2011).

[14] Hoyle, D. M., and S. M. Fielding, "Criteria for extensional necking instability in complex fluids and soft solids. Part I: Imposed Hencky strain rate protocol," J. Rheol. 60, 1347-1375 (2016).

[15] Hoyle, D. M., and S. M. Fielding, "Criteria for extensional necking instability in complex fluids and soft solids. Part II: Imposed tensile stress and force protocols,” J. Rheol. 60, 1377-1397 (2016).

[16] Huang, Q., N. J. Alvarez, A. Shabbir, and O. Hassager, "Multiple cracks propagate simultaneously in polymer liquids in tension," Phys. Rev. Lett. 117, 087801 (2016).

[17] Huang, Q., and O. Hassager, "Polymer liquids fracture like solids," Soft Matter 13, 3470-3474 (2017).

[18] Schwarzl, F., "The numerical calculation of storage and loss compliance from creep data for linear viscoelastic materials," Rheol. Acta 8 , 6-17 (1969).

[19] Wingstrand, S. L., B. Shen, J. A. Kornfield, K. Mortensen, D. Parisi, D. Vlassopoulos, and O. Hassager, "Rheological link between polymer melts with a high molecular weight tail and enhanced formation of Shish-Kebabs," ACS Macro Lett. 6, 1268-1273 (2017).

[20] Gabriel, C., J. Kaschta, and H. Münstedt, "Influence of molecular structure on rheological properties of polyethylenes," Rheol. Acta 37, 7-20 (1998).

[21] Münstedt, H., and F. R. Schwarzl, Deformation and Flow of Polymeric Materials (Springer, Berlin/Heidelberg, 2014), p. 558. 
[22] Román Marín, J. M., J. K. Huusom, N. J. Alvarez, Q. Huang, H. K. Rasmussen, A. Bach, A. L. Skov, and O. Hassager, "A control scheme for filament stretching rheometers with application to polymer melts," J. Non-Newtonian Fluid Mech. 194, 14-22 (2013).

[23] Hengeller, L., Q. Huang, A. Dorokhin, N. J. Alvarez, K. Almdal, and O. Hassager, "Stress relaxation of bi-disperse polystyrene melts," Rheol. Acta 55, 303-314 (2016).

[24] Wingstrand, S. L., M. van Drongelen, K. Mortensen, R. S. Graham, Q. Huang, and O. Hassager, "Influence of extensional stress overshoot on crystallization of LDPE," Macromolecules 50, 1134-1140 (2017).

[25] Wingstrand, S. L., L. Imperiali, R. Stepanyan, and O. Hassager, "Extension induced phase separation and crystallization in semidilute solutions of ultra high molecular weight polyethylene," Polymer 136, 215-223 (2018).

[26] Rasmussen, H. K., A. G. Bejenariu, O. Hassager, and D. Auhl, "Experimental evaluation of the pure configurational stress assumption in the flow dynamics of entangled polymer melts," J. Rheol. 54, 1325-1336 (2010).

[27] Tabuteau, H., S. Mora, M. Ciccotti, C.-Y. Hui, and C. Ligoure, "Propagation of a brittle fracture in a viscoelastic fluid," Soft Matter 7, 9474-9483 (2011).

[28] Freund, L. B., Dynamic Fracture Mechanics (Cambridge University, Cambridge, UK, 1990).

[29] Bird, R. B., R. C. Armstrong, and O. Hassager, Dynamics of Polymeric Liquids, Fluid Mechanics, 2nd ed. (Wiley, New York, 1987).

[30] Gennes, P. G. D., "Soft Adhesives," Langmuir 12, 4497-4500 (1996).

[31] Coppola, S., L. Balzano, E. Gioffredi, P. L. Maffettone, and N. Grizzuti, "Effects of the degree of undercooling on flow induced crystallization in polymer melts," Polymer 45, 3249-3256 (2004).

[32] Balzano, L., N. Kukalyekar, S. Rastogi, G. W. M. Peters, and J. C. Chadwick, "Crystallization and dissolution of flow-induced precursors," Phys. Rev. Lett. 100, 048302 (2008).

[33] Derakhshandeh, M., and S. G. Hatzikiriakos, "Flow-induced crystallization of high-density polyethylene: The effects of shear and uniaxial extension," Rheol. Acta 51, 315-327 (2012).

[34] Roozemond, P. C., Z. Ma, K. Cui§, L. Li, and G. W. M. Peters, "Multimorphological crystallization of shish-kebab structures in isotactic polypropylene: Quantitative modeling of parent-daughter crystallization kinetics," Macromolecules 47, 5152-5162 (2014).

[35] Steenbakkers, R. J. A., G. W. M. Peters, and H. E. H. Meijer, "Rheological modeling of flow-induced crystallization in polymer melts and limitations on classification of experiments," AIP Conf. Proc. 1027, 493-495 (2008).

[36] Roozemond, P. C., M. van Drongelen, and G. W. M. Peters, "Polymer crystallization II," Adv. Polym. Sci. 277, 243-294 (2016).

[37] van Erp, T. B., L. Balzano, A. B. Spoelstra, L. E. Govaert, and G. W. M. Peters, "Quantification of non-isothermal, multi-phase crystallization of isotactic polypropylene: The influence of shear and pressure," Polymer 53, 5896-5908 (2012).

[38] Narimissa, E., and M. H. Wagner, "A hierarchical multimode molecular stress function model for linear polymer melts in extensional flows," J. Rheol. 60, 625-636 (2016).

[39] Wagner, M. H., H. Bastian, P. Hachmann, J. Meissner, S. Kurzbeck, H. Münstedt, and F. Langouche, "The strain-hardening behaviour of linear and long-chain-branched polyolefin melts in extensional flows," Rheol. Acta 39, 97-109 (2000).

[40] Graham, R. S., A. E. Likhtman, T. C. B. McLeish, and S. T. Milner, "Microscopic theory of linear, entangled polymer chains under rapid deformation including chain stretch and convective constraint release," J. Rheol. 47, 1171-1200 (2003).

[41] Doi, M., and S. F. Edwards, The Theory of Polymer Dynamics, 2nd ed. (Oxford University, Oxford, 1988), Vol. 73.

[42] Currie, P., "Constitutive equations for polymer melts predicted by the Doi-Edwards and Curtiss-Bird kinetic theory models," J. NonNewtonian Fluid Mech. 11, 53-68 (1982).

[43] Hassager, O., and R. Hansen, "Constitutive equations for the Doi-Edwards model without independent alignment," Rheol. Acta 49, 555-562 (2010).

[44] Hadinata, C., D. Boos, C. Gabriel, E. Wassner, M. Rüllmann, N. Kao, and M. Laun, "Elongation-induced crystallization of a high molecular weight isotactic polybutene-1 melt compared to shear-induced crystallization," J. Rheol. 51, 195-215 (2007).

[45] Graham, R. S., and P. D. Olmsted, "Coarse-grained simulations of flow-induced nucleation in semicrystalline," Phys. Rev. Lett. 103, 115702 (2009).

[46] Wang, Z., Z. Ma, and L. Li, "Flow-induced crystallization of polymers: Molecular and thermodynamic considerations," Macromolecules 49, 1505-1517 (2016).

[47] Zuidema, H., G. W. M. Peters, and H. E. H. Meijer, "Development and validation of a recoverable strain-based model for flow-induced crystallization of polymers," Macromol. Theory Simul. 10, 447-460 (2001).

[48] Roozemond, P. C., and G. W. M. Peters, "Flow-enhanced nucleation of poly(1-butene): Model application to short-term and continuous shear and extensional flow," J. Rheol. 57, 1633-1653 (2013).

[49] Smook, J., and A. J. Pennings, "Elastic flow instabilities and shishkebab formation during gel-spinning of ultra-high molecular weight polyethylene,” J. Mater. Sci. 19, 31-43 (1984).

[50] Zhang, C., H. Hu, X. Wang, Y. Yao, X. Dong, D. Wang, Z. Wang, and C. C. Han, "Formation of cylindrite structures in shear-induced crystallization of isotactic polypropylene at low shear rate," Polymer 48, 1105-1115 (2007).

[51] Zhao, B., X. Li, Y. Huang, Y. Cong, Z. Ma, C. Shao, H. An, T. Yan, and L. Li, "Inducing crystallization of polymer through stretched network," Macromolecules 42, 1428-1432 (2009). 